\title{
Unwanted Fertility Differentials of Nepalese Mothers
}

\author{
Tika Ram Aryal \\ Central Department of Statistics \\ Tribhuvan Uiversity, Kathmandu, Nepal \\ E-mail: traryal@gmail.com
}

\begin{abstract}
This paper attempts to study unwanted fertility differentials of Nepalese mothers. Parity progression based techniques are used to estimate unwanted fertility of the Nepal Demographic and Health Survey data 2011. An estimate of unwanted total fertility rate was found to be 1.3 births per woman while wanted total fertility rate was 1.8 births per woman, and total fertility rate was 2.67 births per woman during 2009-11. About $31 \%$ of the births were accounted to be stated as unwanted births where $36 \%$ unwanted births in rural women and $25 \%$ urban women. The unwanted percentages were $28 \%, 38 \%$ and $41 \%$ respectively for Tarai, Hills and Mountains women. About 12\% births were unwanted for educated mothers whereas $32 \%$ births were unwanted for illiterate mothers. Unwanted fertility is higher for poorest, illiterate, rural and Mountains women, which might be due to unmet need of contraception, its low use effectiveness, and getting early married as well as the lack of awareness among mothers. The findings may help research scholars, planners, policy-makers and social scientists for designing policy of a country.
\end{abstract}

Key words: Unwanted births, parity progression ratio, fertility rate, differentials, unintended pregnancy.

\section{INTRODUCTION}

The onset of fertility transition is widespread in most of the countries of Asia and Latin America, and has recently begun the transition in some countries in Africa where the recent rapidly declining patterns of fertility transition are mainly due to the changes in reproductive attitudes and behaviors among educated and well-off populations (Aryal \& Subedee, 2011). It is well-known fact that in fertility transition, the most important prerequisites factors are considered as rising aspirations, changing in the functions of family, and rising costs of rearing and schooling of children, and which are expected to be associated with urban lifestyles (Aryal, 2002). The situation of developed countries with low birth rates have raised concerns about population decline, contraction in the size of the labor force, excessive levels of population ageing and erosion of overall population size and national influence in world affairs (Aryal, 2002; Keilman, 2006).

The reproduction process in human being normally takes place during teens of life; however, there is a big variation in childbearing process around the globe (Aryal, 2012; Riley et al. 1993). Fertility behavior among females is changing over time and numerous studies have been conducted all over the world (Diamond \& Rutenberg, 1995; Vander, 1992). Unintended pregnancy rates remain high in the United States; with recent data showing that one-half of all pregnancies are unintended (Finer \& Henshaw, 2006). Indeed, poor and lesseducated women are more likely to have an unintended pregnancy than rich and more educated women; little is known about the role that discontinuation of contraception because of dissatisfaction plays in contributing to this disparity (Finer \& Henshaw, 2006). A large proportion of unintended pregnancies are not solely the result of couples never having used birth control (Kost et al. 2008). An unintended pregnancy, consistency and failure also vary by race and education, with minority and less-educated women contraception less than white and more-educated women and black and poorer women experiencing much higher rates of contraceptive failure than white and more affluent women (Kost et al. 2008; Frost et al. 2007).

The unintended pregnancy rate for black women also has important implications for race differences in having more children than intended and the race differences between black and white women in the likelihood of overachieving fertility intentions (versus achieving intentions) were largely eliminated after accounting for experiencing births from pregnancies that the women themselves retrospectively called unwanted or mistimed (Guzzo \& Hayford, 2011; Morgan \& Rackin, 2010). The literature identifies striking race and education differences in the types of birth control used (Mosher \& Jones, 2010). The high rate of contraceptive sterilization as a current form of birth control among black and less-educated women reflects the desire for a long-term method with a lower risk of failure (Borrero et al. 2010; Trussell, 2011).

Unwanted fertility is higher among the populations of 
higher level of fertility rates as well as low levels of contraceptive practices (Aryal, 2005; Kulkarni \& Choe, 1998; Riley et al. 1993). A reduction in unwanted births has important social, health and demographic consequences. Preventing unwanted births at the individual level enhances well being of women and their children whereas elimination of unwanted births at the societal level leads to substantial reductions in fertility and rate of population growth (Bongaarts, 1997; Kulkarni \& Choe, 1998). A study of unwanted fertility and family planning impact on fertility is an important issue in determining useful tools or indicators for designing policy and planning to reduce the overall level of fertility in the country among different socioeconomic setups populations (Kanitkar \& Radkar, 2000; Pathak, 1998; UN, 1997, 1998).

Total fertility rate is a refined and reliable measure of fertility in a population and has recently been studied through parity progression ratios (PPR), which of course, reflect the tempo of cohort fertility (Aryal, 2006). This approach of measuring period fertility, called period parity progression ratio (PPPR), gives an additional advantage of looking at trends in TFR and facilitates in making comparisons separately regarding progression of a specific parity to higher order parity (Aryal \& Subedee, 2011; Pandey et al. 1997).

In Nepal, total fertility rate declined from 4.6 births per woman in 1996 to 4.1 births per woman in 2001 to 3.1 births per woman in 2006 and to reach 2.6 births per woman in 2011. Infant mortality rate declined from 172 in 1971, to 117 in 1981 to 97 in 1991, to 64 deaths per 1000 live births in 2001 to 48 deaths per 1000 live births in 2006 and to 46 deaths per 1000 live births in 2011 (CBS, 2011; MOPH, 2011). Maternal mortality ratio was high in 1990s and it declined substantially from 830 in 1991, to 539 in 1996, to 281 in 2006 and 229 deaths per 100000 live births in 2011. The life expectancy of the population has substantially increased from 42 years in 1971 to 66 years in 2011 (Aryal, 2011; CBS, 2011; $\mathrm{MOH}, 2006$; MOPH, 2011).

Preventing unwanted births at individual level enhances the well being of women and their children whereas elimination of unwanted births at the societal level leads to substantial reductions in fertility and rate of population growth (Bongaarts, 1997; Kulkarni \& Choe, 1998). Bongaarts $(1990,1997)$ examined the level of unwanted fertility using data from 48 World Fertility Survey and Demographic and Health Survey and he found that the proportion of unwanted births was high in countries with intermediate level of fertility.

Most commonly used measures of unwanted fertility have relied heavily on the reported ideal number of children or the reported wanted status of recent births.
As Bongaarts (1990) pointed out that it underestimates actual level of unwanted fertility and consequently he introduced a measure to estimate the unwanted fertility using information on desire for more children, which is conceptually a complicated procedure (Kulkarni \& Choe, 1998). A study reported the wanted TFR of 2.9 against the total fertility rate of 4.6 births per woman in 2006 in Nepal (MOH, 1997) based on the data of ideal family size if all unwanted births were avoided. Likewise, the level of wanted fertility was 1.8 against the total fertility rate of 2.6 births per woman in 2011 (MOPH, 2011).

Measuring the level of unwanted fertility accurately and identifying the factors associated with variations in unwanted fertility provide valuable information to policy-makers concerned with the welfare of women and children and reduction in fertility (Kanitkar \& Radkar, 2000; Morgan \& Rackin, 2010). A number of studies reported that unwanted births constitute 20 to 30 per cent of total births in recent years in most of the developing countries (Bankole \& Westoff, 1995; UN, 1987). It is pointed out that the parity progressionbased wanted TFR may be free from biases due to rationalization which uses information on whether a woman wants another child or not (Bongaarts, 1990; Kulkarni \& Choe, 1998). In this context, the aim of this paper is to study the differentials of unwanted fertility of Nepal by using the data of Nepal Demographic Health Survey (NDHS) 2011.

\section{MATERIALS AND METHODS \\ Data}

This paper uses the extracted data from Nepal Demographic and Health Survey (NDHS) 2011. The 2011 NDHS collected demographic and health information from a nationally representative sample of 10,826 households, which yielded completed interviews with 12,674 women age 15-49 in all selected households (MOPH, 2011). In survey, one more individual questionnaire was used to collect information on birth histories, ideal family size, wanted more child and unwanted children etc. The reference date of the survey was taken as Chaitra 2068 (as of April, 2011) so that births occurred after this date has been excluded in this analysis.

\section{Estimation of unwanted fertility}

Unwanted births are those for which women reported that right before they became pregnant, they did not want to have any births at any point in the future (a number failure), while mistimed births are those identified as occurring any time earlier than desired (a timing failure). Unintended births are then the sum of all births identified as unwanted or mistimed (Guzzo \& Hayford, 2011). Measurement of unwanted 
fertility through indirect techniques has received great attention of demographers. Kulkarni and Choe (1998) used parity progression based measures to estimate unwanted fertility. This procedure is applied to estimate the unwanted fertility for Nepal. Their procedure and adjustment to it are as follows. Details may be found in Kulkarni and Choe (1998).

Let $\mathrm{P}(\mathrm{i})$ be the period parity progression ratios for women of parity $i$, and $\mathrm{W}(\mathrm{i})$ be the unadjusted wanted parity progression ratio for women of parity $i$, which is calculated as the proportion of women of parity $i$ who want at least one more child. The wanted fertility can be computed from the set of W(i). The result, however, will not be an accurate measure of wanted fertility because the denominator of W(i), which consists of all women of parity i, includes women who already have borne some unwanted children. Thus, it is necessary to adjust the denominator to obtain the proportion of women who want more children among those who have no unwanted children.

If $R(i)$ be the proportion of women reaching parity $i$ in an assumed cohort, then

$$
\begin{aligned}
& \mathrm{R}(0)=1, \text { and } \\
& R(i)=R(i-1) P(i-1) \quad i>0
\end{aligned}
$$

where $\mathrm{P}(\mathrm{i}-1)$ be the period parity progression ratios for women of parity (i-1).

Let $R^{*}(i)$ be the proportion of women who want to reach parity i, so that

$$
\begin{aligned}
& R^{*}(i)=1, \text { and } \\
& R^{*}(i)=R(i-1) W(i-1) i>0
\end{aligned}
$$

where $\mathrm{W}(\mathrm{i}-1)$ be the unadjusted wanted parity progression ratio for women of parity (i-1).

The adjustment factor, A(i) can be written as

$$
A(i)=\frac{R^{*}(i)}{R(i)}
$$

and $\mathrm{W}(\mathrm{i})$ can be adjusted as

$$
W^{*}(i)=\frac{W(i)}{A(i)}
$$

Using the value of adjusted wanted parity progression ratio, the wanted total fertility rate can be obtained as WTFR $=\mathrm{W}^{*}(0)+\mathrm{W}^{*}(0) \mathrm{W}^{*}(1)+\mathrm{W}^{*}(0) \mathrm{W}^{*}(1) \mathrm{W}^{*}(2)+\ldots(5)$

Finally, an unwanted total fertility rate (UWTFR) may be obtained by taking the difference between TFR and WTFR i.e.

UWTFR $=$ TFR - WTFR
TFR is the total fertility rate and WTFR is the wanted total fertility rate.

\section{RESULTS AND DISCUSSION}

The estimates of total fertility rate (TFR), wanted total fertility rate (WTFR) and unwanted total fertility rate for the period of three years preceding the survey date i.e. 2008-11 according to the characteristics of mothers are given in the Table 1. An estimate of UWTFR was found to be 1.3 births when WTFR was 1.8 births per woman and TFR was 2.67 births per woman by PPR during 2008-10. About 31 per cent of the births were found to be stated as unwanted births included in the survey date i.e. 2008-11. This is consistent with the findings of several studies among developing countries as well as underdeveloped

countries which reported unwanted births to be around 20 to 30 per cent of the total births in recent years (Bankole \& Westoff, 1995; Feeney \& Yu, 1987).

Wanted total fertility rate was found to be higher (by about a child) among rural women (1.8 births per woman) than that of urban women (1.2 births per woman). The TFRs for rural and urban women were 2.8 and 1.6 births per woman respectively. The unwanted births were accounted to be 36 per cent among rural women and 25 per cent among urban women. Similarly, the percentage of unwanted TFR was found to be 28 , 38 and 41 per cent respectively among women of Tarai, Hills and Mountains. The unwanted birth was found to be higher among Mid-western (43.75\%) and followed by Far-western (35.70), Western (32.0\%), Central (32.0\%) and Eastern (28.0\%) development regions. A strong negative relationship between wanted fertility and education can be observed. A low level of WTFR was found among educated women whereas UWTFR was found higher among illiterate women. A lower amount of unwanted birth among educated and urban women may be due to motivation and ability to use contraception by women who do not want more children. Percentage of unwanted births was found to be 11.8 among educated women whereas it was 32 per cent among uneducated mothers, which imply that as increasing the levels of education the less chance to have unwanted births among Nepalese mothers. The UWTFR was found to be highest among women residing in Mountains (1.4 births per woman) followed by Hills (1.0 births per woman) and Tarai ( 0.7 births per woman) whereas the WTFR (TFR) was found to be 2.0(3.4) births per woman, 1.6(2.6) births per woman and 1.8(2.5) births per woman for women residing in Mountains, Hills and Tarai belts respectively. 
Table 1 Wanted and unwanted total fertility rate according to the characteristics of women NDHS (2008-11)

\begin{tabular}{|c|c|c|c|c|}
\hline \multirow{2}{*}{ Characteristics } & \multirow{2}{*}{ Obs. TFR } & \multicolumn{2}{|c|}{ Estimated TFR } & \multirow{2}{*}{$\%$ of UTFR } \\
\hline & & WTFR & UWTFR & \\
\hline \multicolumn{5}{|l|}{ Residential status } \\
\hline Urban & 1.6 & 1.2 & 0.4 & 25.00 \\
\hline Rural & 2.8 & 1.8 & 1.0 & 35.71 \\
\hline \multicolumn{5}{|l|}{ Ecological belt } \\
\hline Mountain & 3.4 & 2.0 & 1.4 & 41.18 \\
\hline Hill & 2.6 & 1.6 & 1.0 & 38.46 \\
\hline Tarai & 2.5 & 1.8 & 0.7 & 28.00 \\
\hline \multicolumn{5}{|c|}{ Development region } \\
\hline Eastern & 2.5 & 1.8 & 0.7 & 28.00 \\
\hline Central & 2.5 & 1.7 & 0.8 & 32.00 \\
\hline Western & 2.5 & 1.7 & 0.8 & 32.00 \\
\hline Mid-western & 3.2 & 1.8 & 1.4 & 43.75 \\
\hline Far-western & 2.8 & 1.8 & 1.0 & 35.71 \\
\hline \multicolumn{5}{|l|}{ Schooling } \\
\hline No education & 3.7 & 2.5 & 1.2 & 32.43 \\
\hline Primary & 2.7 & 1.9 & 0.8 & 29.63 \\
\hline Some secondary & 2.1 & 1.6 & 0.5 & 23.81 \\
\hline SLC and above & 1.7 & 1.5 & 0.2 & 11.76 \\
\hline \multicolumn{5}{|l|}{ Economic status } \\
\hline Poorest & 4.1 & 2.1 & 2.0 & 48.78 \\
\hline Poor & 3.1 & 2.0 & 1.1 & 35.48 \\
\hline Middle & 2.7 & 2.0 & 0.7 & 25.93 \\
\hline Rich & 2.1 & 1.6 & 0.5 & 23.81 \\
\hline Richest & 1.5 & 1.2 & 0.3 & 20.00 \\
\hline Total & 2.6 & 1.8 & 0.8 & 30.77 \\
\hline
\end{tabular}

UTFR was found to be 1.2 births among illiterate mother whereas it was .2 births per woman among women of SLC and above education. The unwanted fertility level was found to be decreased with increased level education where the unwanted birth was found to be higher among illiterate women $(32.43 \%)$ and followed primary $(29.63 \%)$, some secondary $(23.81 \%)$ and SLC and higher education $(11.76 \%)$, which implies that with a increase in educational level with less chance to have unwanted births and thereby decreased levels of wanted fertility and total fertility rates. Total fertility rates were found to be 3.7, 2.7, 2.1 and 1.7 births per women respectively for uneducated, primary educated, some secondary educated and SLC and above educated women whereas wanted TFR respectively was found to be $2.5,1.9,1.6$ and 1.5 births per women.

UTFR was found to be 2 births among poorest mother whereas it was .3 births per woman among richest mothers. The unwanted fertility level was found to be decreased with increased level of economic status of mothers where the unwanted birth was found to be higher among poorest women $(48.78 \%)$ and followed by poor $(35.48 \%)$, middle $(25.93 \%)$, rich $(23.81 \%)$ and richest $(20.0 \%)$, which implies that with a increase in economic quintile groups with less chance to have unwanted births and thereby decreased levels of wanted fertility and total fertility rates. Total fertility rates were found to be 4.1, 3.1, 2.7, 2.1 and 1.5 births per women respectively for poorest, poor, middle, rich and richest women whereas wanted TFR respectively was found to be 2.1, 2.0, 2.0, 1.6 and 1.2 births per women. A higher unwanted fertility among women of poorest, illiterate, rural and Mountains region might be due to the unmet need of contraception and its low use effectiveness, getting early marriages and lack of awareness about unwanted fertility as well as a large number of births. 

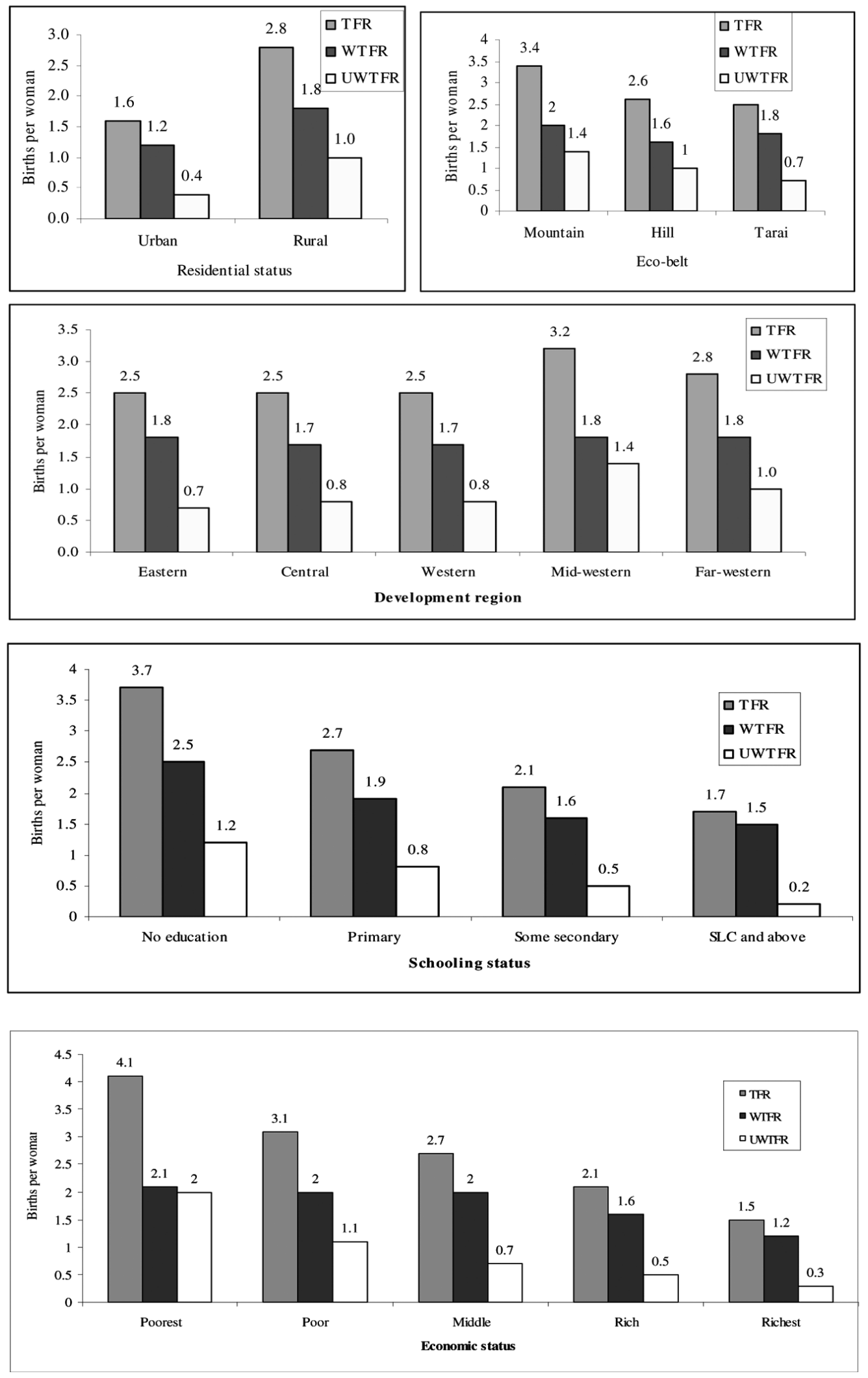

Fig. 1. Wanted, unwanted and TFR by characteristics of mothers 


\section{CONCLUSION}

Unwanted total fertility rates have been computed according to characteristics of women. An estimate of UWTFR was found to be 1.3 births when WTFR was 1.8 births per woman and TFR was 2.67 births per woman during 2008-10. About 31 per cent of the births were found to be stated as unwanted births. The unwanted births were accounted to be 36 per cent among rural women and 25 per cent among urban women. Similarly, the percentage of unwanted TFR was found to be 28 , 38 and 41 per cent respectively among women of Tarai, Hills and Mountains. A strong negative relationship between wanted fertility and education can be observed where UWTFR was found higher among illiterate women. Percentage of unwanted births was found to be 11.8 among educated women whereas it was 32 per cent among uneducated mothers, which imply that as increasing the levels of education the less chance to have unwanted births among Nepalese mothers. The unwanted fertility level was found to be decreased with increased level of economic status of mothers. A higher unwanted fertility among women of poorest, illiterate, rural and Mountains region might be due to the unmet need of contraception and its low use effectiveness, getting early marriages and lack of awareness.

\section{ACKNOWLEDGEMENTS}

I would like to thank the University Grants Commission of Nepal for financial supports

\section{REFERENCES}

Aryal, M. and Subedee, H.R. 2011. Socio-cultural and proximate determinants of fertility of Nepal. Peaceworks: An Interdisciplinary Journal 1(1), Nepal Issue (1) : 1-12.

Aryal, T.R. 2002. Some Demographic Models and Their Applications with Reference to Nepal. Ph.D. thesis, Department of Statistics, BHU, India.

Aryal, T.R. 2005. Measurement of wanted and unwanted fertility in Nepal: pattern and differentials. Curriculum Development Journal 23(37): 98-103.

Aryal, T.R. 2006. The fertility impact of changes in the timing of childbearing in Nepal. Nepal Journal of Science and Technology 7: 47-52.

Aryal, T.R. 2011. Fertility Dynamics of Nepal. Ekta Books \& Distributors Pvt. Ltd. Thapathali, Kathmandu, Nepal.

Aryal, T.R. 2012. Reproductive Behaviors: A Study on Differentials, Determinants and Distribution of Ages at Menarche, Marriage, Motherhood and Menopause. Publisher: Roshan \& Raman and Distributors: Gyankunja Pvt. Ltd. Kirtipur, Kathmandu, Nepal.

Bankole, A. and Westoff, C.F. 1995. Childbearing Attitudes and Intentions: Demographic and Health Surveys Comparative Studies. (No. 17) Columbia, Maryland:
IRD/Macro International.

Bongaarts, J. 1990. The measurement of wanted fertility. Population and Development Review 16(3):487-506

Bongaarts, J. 1997. The Proximate Determinants of Unwanted Childbearing in the Developing World. Paper presented at the 1997 Annual Meeting of the Population Association of America, Washington, D.C., 27-29 March.

Bongaarts, J. and Feeney, G. 1998. On the quantum and tempo of fertility. Population and Development Review 24(3) :271-291.

Borrero, S., Moore, C.G., Qin, L., Schwarz, E.B., Akers, A., Creinin, M.D., and Ibrahim, S.A. 2010. Unintended pregnancy influences racial disparity in tubal sterilization rates. Journal of General Internal Medicine 25:122-128.

CBS. 2011. Population Census 2011 of Nepal: Preliminary National Report. Central Bureau of Statistics, Kathmandu, Nepal.

Diamond, I. and Rutenberg, N. 1995. Recent trends in fertility in Botswana. Journal of International Development 7(1) : 145-161.

Finer, L.B. and Henshaw, S.K. 2006. Disparities in rates of unintended pregnancy in the United States, 1994 and 2001. Perspectives on Sexual and Reproductive Health 38: 90-96.

Frost, J.J., Singh, S. and Finer, L.B. 2007. Factors associated with contraceptive use and nonuse, USA, 2004. Perspectives on Sexual and Reproductive Health 39:90-99.

Guzzo, K.B. and Hayford, S. 2011. Fertility following an unintended first birth. Demography 48:1493-1516.

Kanitkar, T. and Radkar, A. 2000. Unwanted Pregnancies and the Role of Induced Abortions in India. Paper presented at the Indian Association for the Study of Population, Millennium Conference on Population, Development and Environment Nexus, (pp. 14-16), February 2000. PHD, House, New Delhi.

Keilman, N. 2006. Demographic translation. From period to cohort perspective and back. In: Caselli, G., Vallin, J. \& Wunsch, G. (Eds.). Demography: Analysis and Synthesis : 215-225. I. London: Academic Press.

Kim, Y.J. and Schoen, R. 2000. On the quantum and tempo of fertility: limits to the Bongaarts-Feeney adjustment. Population and Development Review 26(3):554-559.

Kost, K., Singh, S., Vaughan, B., Trussell, J., and Bankole, A. 2008. Estimates of contraceptive failure from the 2002 National Survey of Family Growth. Contraception 77: 10-21.

Kulkarni, S. and Choe, M.K. 1998. Wanted and Unwanted Fertility in Selected States of India. National Family Health Survey Subject Reports, Number 6, East-West Center Program on Population Honolulu, Hawaii, 


\section{U.S.A.}

MOH. 1997. Nepal Family Health Survey 1996 Report. Ministry of Health, Kathmandu, Nepal

MOPH. 2006. Nepal Demographic and Health Survey 2006 Report. Ministry of Population and Health, Kathmandu, Nepal.

MOPH. 2011. Nepal Demographic and Health Survey 2011 Preliminary Report. Ministry of Population and Health. Kathmandu, Nepal.

Morgan, P.S., and Rackin, H. 2010. The correspondence between fertility intentions and behavior in the United States. Population and Development Review 36: 91118.

Pathak, R.S. 1998. Family planning programs effort, contraceptive prevalence and fertility: the case of Nepal in South Asia. Nepal Population Journal 7(6) : 45-50.
Riley, A.P., Samuelsion, J.L. and Huffman, S.L. 1993 The relationship of age at menarche and fertility in undernourished adolescents. Biomedical and demographic determinants of reproduction (Ed. R. Grey et al.): 50-84.

Trussell, J. (2011). Contraceptive failure in the United States. Contraception 83:397-404.

UN. 1997. Family Building and Family Planning Evaluation. Department of Economic and Social Affairs: Population Division, ST/ESA/SER.R/148, New York, U S A.

UN. 1998. Levels and Trends of Contraceptive Use as Assessed in 1998. Department of Economic and Social Affairs: Population Division, ST/ESA/ SER.A/190, New York, USA.

Vander, P.C. 1992. Regional patterns of fertility transition in Botswana. Geography 77(2) : 109122 